Rev. Adm. Saúde Vol. 17, № 68, Jul. - Set. 2017

http://dx.doi.org/10.23973/ras.68.38

ARTIGO ORIGINAL

\title{
O fator humano na organização: características motivacionais da equipe de enfermagem de um hospital público do interior de Rondônia
}

The human factor in the organization: motivational characteristics of nursing team of a public hospital in the inland region of Rondônia

\section{Luciano Santos Magalhães ${ }^{1}$, Fernanda Heringer Moreira Rosa ${ }^{2}$}

1. Psicólogo pela Faculdade de Rolim de Moura, mestre em administração pública pela Universidade Federal de Rondônia. Servidor da Universidade Federal de Rondônia

2. Psicóloga pela UFJF, mestre em gerontologia pela Unicamp. Doutoranda em psicologia do desenvolvimento na UFMG

\section{RESUMO}

Neste trabalho, abordou-se a teoria da expectativa, que sustenta que a motivação dependerá dos resultados do trabalho que o colaborador obtenha. Esta pesquisa procurou verificar em profissionais da equipe de enfermagem de um hospital público municipal do interior de Rondônia sua motivação e o que os fazem engajar no trabalho. Foi utilizado como instrumento de pesquisa o IMST e um questionário sociodemográfico. A amostra foi de 8 participantes, tendo 3 enfermeiros, 4 técnicos e 1 auxiliar de enfermagem. Tal amostragem em cotas procurou ter a representação de todas as formações profissionais desta população, mas os resultados foram analisados num todo. A força motivacional encontrada se inseriu num intervalo de moderado a alto, próximo de um valor mediano. Os fatores que levam estes profissionais a um maior engajamento são os de autoexpressão e realização pessoal, relacionado à valência; segurança e dignidade, relacionado à expectativa; e envolvimento, relacionado à instrumentalidade. Conclui-se assim, que a instituição pesquisada deve atentar para a motivação de seus profissionais de enfermagem, particularmente ao instrumental que esses profissionais visualizam ser o seu trabalho. 
Palavras-chave: perfil motivacional; equipe de enfermagem; teoria da expectativa.

\begin{abstract}
In this research, we approached the theory of expectation, which maintains that the motivation will depend on the results that the employee obtains. The research sought to verify in professionals of the nursing team of a municipal public hospital in the interior of Rondônia their motivation and what makes them engage in work. The IMST and a sociodemographic questionnaire were used as a research tool. The sample was 8 participants, with 3 nurses, 4 technicians and 1 nursing assistant. Such sampling in quotas sought to represent all professional backgrounds of this population, but the results were analyzed globally. The motivational force found was within a range of moderate to high, close to a median value. The factors that lead these professionals to greater engagement are those of self-expression and personal fulfillment, related to valence; security and dignity, related to the expectation; and involvement, related to instrumentality. It is concluded that the research institution must pay attention to the motivation of its nursing professionals, particularly to the instruments that these professionals visualize to be their work.
\end{abstract}

Keywords: motivational profile; nursing staff; expectancy theory.

\title{
INTRODUÇÃO
}

O papel e a importância das pessoas na organização são fundamentais. Nesse sentido, cabe à organização a gestão de seu pessoal para a qualidade e quantidade da produção, bem como para a qualidade de vida de seus colaboradores.

As pessoas são, portanto, muito determinantes no sucesso da organização. É preciso tê-las motivadas para a consecução dos objetivos organizacionais, pois elas promovem um clima organizacional positivo, o que leva a empresa a resultados, alcançando suas metas.

Estudar a motivação de profissionais de saúde, particularmente do Sistema Único de Saúde, é bastante pertinente; deles depende parte da qualidade de vida da comunidade. Se as pessoas são essenciais nas organizações, em saúde pública elas são ainda mais determinantes. Afinal, esses profissionais estão motivados? 0 que os fazem engajar no trabalho?

Espera-se encontrar um valor de força motivacional menor. Provavelmente esses profissionais têm dificuldade de perceberem seu desempenho como instrumental para a realização de suas expectativas.

O presente trabalho objetivou aferir a motivação de colaboradores que compõem a equipe de enfermagem de um hospital público municipal do interior do estado de 
Rondônia, identificar fatores para o engajamento no trabalho e analisar a satisfação dos mesmos, para a qualidade de vida desses profissionais e para o bom andamento dos trabalhos da organização na qual estão inseridos.

Serão apresentados a seguir os aspectos teóricos que envolvem o estudo da motivação, particularmente a concepção que o modelo contingencial de Vroom aborda. Bem como a gestão de pessoas a partir dessa proposição teórica e estudos de aspectos motivacionais em profissionais de saúde.

\section{As organizações e as pessoas}

O papel e a importância das pessoas nas organizações são inegáveis. Para CHIAVENATO (2010, p. 5) "[...] as organizações funcionam por meio das pessoas, que delas fazem parte e que decidem e agem em seu nome".

Tendo em vista a preponderância do fator humano na consecução dos objetivos organizacionais, CHIAVENATO (2009, p. 70) o denomina de "capital humano das organizações". A forma de gerir esse capital humano é decisiva. As pessoas fazem a empresa alcançar resultados ao gerar um clima organizacional positivo; isso faz a empresa andar e alcançar suas metas (ARAÚJO, 2008).

Preocupadas com a gestão de seu pessoal, as organizações empreendem estudos sobre motivação, que se dão desde o início do século XX, com estudos mais aprofundados em meados da década de 1950 (MARRAS, 2000) e há diversas teorias. Diante da vasta literatura, que veem a motivação através de diferentes abordagens, TRIBETT E RUSH (1984 apud PÉREZ-RAMOS, 1990) traz a classificação que trata tais teorias como de conteúdo e de processo.

As teorias de conteúdo entendem a motivação a partir das necessidades das pessoas. A satisfação dessas necessidades é o mecanismo motivacional utilizado. Tais teorias partem do pressuposto que há necessidades humanas e que estas dirigem o comportamento, que busca a sua satisfação (PÉREZ-RAMOS, 1990). Já nas teorias de processo procura-se compreender os aspectos psicológicos que permeiam o comportamento motivacional, buscando-se entender o comportamento através de seu processo: como começa, se conserva e termina (CONDIM; SILVA, 2004).

As teorias de conteúdo mais conhecidas são a hierarquia das necessidades de Maslow, teoria das necessidades aprendidas ou adquiridas de MCCLELLAND e teoria dos dois fatores de Herzberg (PÉREZ-RAMOS, 1990; GIBSON et al., 2006; SILVA, 2006). Quanto às teorias de processo, os modelos mais conhecidos são a teoria da equidade de Adams, teoria da fixação de objetivos de Locke e o modelo contingencial de Vroom (PÉREZ-RAMOS, 1990; ROBBINS, 2005).

Esta pesquisa se embasará numa teoria de processo, especificamente na teoria da expectativa de Vroom (1964). Se referindo à Vroom, CHIAVENATO $(2009$, p. 56) coloca que em sua proposta ele "[...] rejeita noções preconcebidas e reconhece as diferenças individuais". 
Serão abarcadas, conforme Vroom (1964), os seguintes aspectos: a valência, a Instrumentalidade, a expectativa, a força motivacional e resultados do trabalho. $\mathrm{O}$ autor define:

- a valência é a atração ou repulsão do trabalhador por certa atividade, conforme esta lhe traga ou não resultados. Dessa forma, a valência ou valoração de cada atividade está no seu resultado esperado.

- a instrumentalidade é a correspondência entre os objetivos individuais e a produtividade do colaborador, ou seja, como o profissional usa seu trabalho para conseguir o que almeja. Sendo que isso, o que se almeja, é expectativa.

- a expectativa é o próprio desejo, conforme os objetivos pessoais.

- a força motivacional é o esforço do colaborador para a sua motivação. O autor considera que a força motivacional pode ser representada pela fórmula:

$$
\mathrm{FM}=\mathrm{E}\left[\Sigma \mathrm{V}_{\mathrm{i}} \mathrm{li}_{\mathrm{i}}\right]
$$

Na fórmula: $F M=$ força motivacional, $E=$ expectativa e $\mathrm{I}=$ instrumentalidade.

E ainda resultados do trabalho, definido como o que a organização pode oferecer para os seus colaboradores: como viagens, licenças, férias, prazer, outros.

O que Vroom teoriza pode ser exemplificado num trabalhador que deseja ter um veículo (expectativa), para tanto ele procura vender mais produtos (instrumentalidade), já que recebe comissão, onde certos produtos têm maior ou menor índice percentual (valência). Não necessariamente esta dinâmica pode ser ilustrada para bens materiais; algumas pessoas trabalham para se sentirem úteis, por prazer no trabalho, por conta da interação social com colegas e clientes, entre outras expectativas. Naturalmente, as valências e expectativas divergem para cada indivíduo, assim como a Instrumentalidade que cada profissional faz do seu trabalho. Portanto, mesmo permitindo analisar um grupo, a teoria da expectativa possibilita também a visualização do perfil individual.

Os termos interagem. Fala-se, dessa forma, em valência dos resultados do trabalho, instrumentalidade dos resultados do trabalho e expectativa dos resultados do trabalho, tudo converge para resultar na força motivacional.

\section{Gestão de pessoas à luz da teoria da expectativa}

A teoria da expectativa é uma ferramenta poderosa para a gestão de pessoas. GIBSON ET AL. (2006) apresentam três ações que o gestor deve tomar. Primeiro, o gestor deve alinhar as expectativas dos seus colaboradores à sua capacidade de 
realizá-las. Situações de grupo e tarefas acima de sua capacidade podem ser inadequadas. Segundo, o gestor precisa identificar aspectos que os seus geridos valorizam, levando-se em conta que podem ser fatores muito diferentes para cada caso. Terceiro, é preciso vincular os objetivos da organização com os resultados dos seus subordinados; assim, permitindo que os colaboradores usem seu desempenho como instrumental para alcançar seus objetivos, que estariam em consonância com as metas organizacionais. Dessa forma, o profissional alcança resultados pessoais e também para a organização.

GIBSON ET AL. (2006, p. 151) complementam, afirmando que "o trabalhador avalia a informação disponível e toma decisões de acordo com o valor das consequências e das suas próprias possibilidades de obtenção do resultado preferido".

Para melhor compreensão da teoria da expectativa aplicada à gestão de pessoas, CHIAVENATO (2009) traz a seguinte representação, que esquematiza como se dá esse processo.

Na Figura 1, a seguir, é possível perceber como se dá o processo na qual o colaborador investe esforço, por conta de suas expectativas, o que gera maior desempenho, sendo que esse melhor desempenho (instrumentalidade) leva a resultados intermediários. Estes podem ser, por exemplo, um cargo com maior remuneração, que por sua vez traz resultados fins como bens, aceitação no grupo (resultados do trabalho). A valência aqui se insere nesses meios que mais trazem resultados e eles, naturalmente, serão preferidos pelo colaborador.

Esse modelo de gestão apresenta alguma dificuldade de aplicação na gestão pública tradicionalista. Numa pesquisa, que comparou as remunerações de setores públicos e privados ao longo da década de 1990, entre suas conclusões destaca-se "[...] a inexistência de mecanismos que permitam remunerar, de forma diferenciada, pessoas ou órgãos que possuam competências e apresentem desempenho destacados [...]" (MARCONI, 2003, p. 35).

Figura 1. Representação do modelo de expectativa

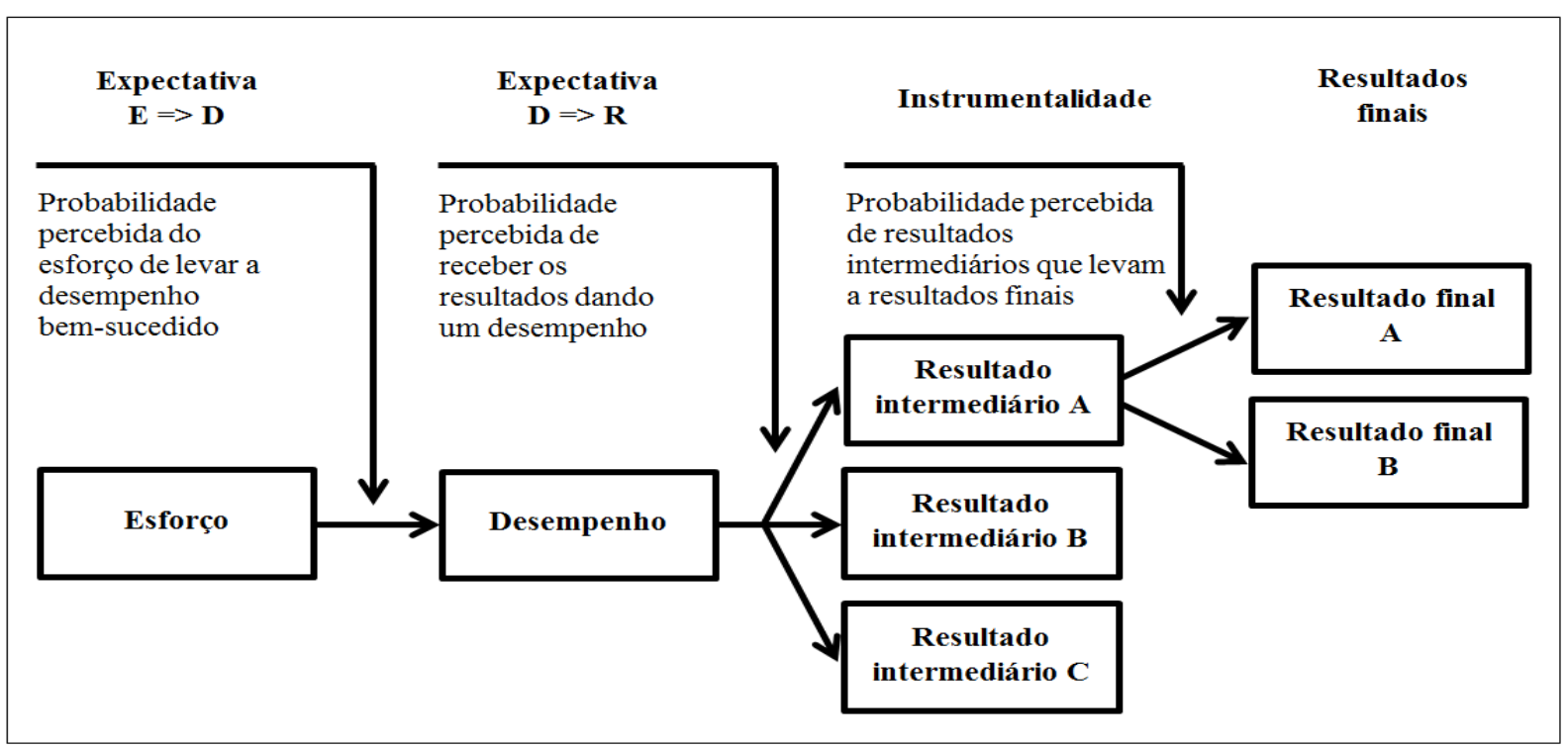


Fonte: CHIAVENATO (2009, p. 58)

\section{Estudos de motivação no Brasil a partir da teoria da expectativa}

Inicialmente, não havendo instrumento adequado no Brasil para o estudo da motivação à luz da teoria da expectativa, foi necessário desenvolver um instrumento para tal. Este instrumento é o Inventário de Motivação e Significado do Trabalho (IMST) (BORGES; ALVES FILHO, 2001, 2003). A princípio os estudos procuraram a validação do instrumento e, naturalmente, aferiram aspectos motivacionais, tais aspectos serão apresentados a seguir.

BORGES E ALVES FILHO (2001) numa pesquisa em Natal (Rio Grande do Norte) com 642 participantes, 487 profissionais de saúde e 155 bancários, constatou que estes valorizam a justiça no trabalho (valência), esperando que ela ocorra (expectativas), porém não usam seu desempenho para que a justiça no trabalho aconteça (instrumentalidade).

Os mesmos autores (BORGES; ALVES FILHO, 2003) realizaram outra pesquisa com uma amostra de 525 participantes, tendo em sua composição 55,2\% de profissionais de saúde, $23,4 \%$ de trabalhadores de uma distribuidora de petróleo e $21,3 \%$ de bancários de um banco de economia mista. Identificaram o grau de valorização da justiça no trabalho nesta ordem: primeiro os petroleiros, depois os bancários e os profissionais de saúde. Para a valorização da autoexpressão e realização pessoal, novamente os petroleiros vêm em primeiro lugar, seguido dos profissionais de saúde e bancários. Já para o bem-estar socioeconômico, os profissionais de saúde são os que mais o valorizam, seguido dos petroleiros e por fim os bancários, porém não percebem seu desempenho como forma de conseguilo, mesmo o valorizando tanto. Inclusive este foi o fator mais esperado para os três públicos.

CALDAS E ALVES FILHO (2007) realizaram uma pesquisa com profissionais técnico-administrativos de uma instituição de ensino superior de Natal. Para esta população os autores constataram que os participantes valorizam especialmente o seu sustento pessoal e familiar, também sua autoexpressão e prazer nas atividades (valências). Que esses funcionários esperam que a autonomia nas decisões, sentimento de dignidade e cumprimento adequado de tarefas Ihes proporcionará respeito, prestígio e independência econômica (expectativa). Ainda, verificaram que os participantes não percebiam claramente o seu desempenho como instrumental para alcançar suas expectativas (instrumentalidade).

\section{Aspectos motivacionais de profissionais de saúde}

No contexto da saúde, com a abordagem de Vroom, foram localizados apenas o estudo de GUARDA (2009) e de BORGES E ALVES FILHO (2001, 2003). Estes dois últimos já apresentados anteriormente, pois não tinham apenas profissionais de saúde como população pesquisada. 
GUARDA (2009), pesquisou médicos de equipes de saúde da família de Recife (Pernambuco), obteve força motivacional média de 80,52 e identificou como fatores para o engajamento no trabalho responsabilidade, relacionado à expectativa; sobrevivência pessoal, relacionado à valência; e envolvimento relacionado à instrumentalidade. Não houve correlação entre motivação e aspectos socioeconômicos.

Para melhor compreensão do panorama motivacional de profissionais de saúde, particularmente da área da enfermagem, é interessante visualizar outras pesquisas afins, mesmo não sendo à luz da teoria da expectativa ou numa outra abordagem dentro das teorias de processo. Nesse sentido, cabe a consideração de PÉREZRAMOS (1990) para tão pouca produção científica. O autor afirma que, apesar da alta aceitação acadêmica das teorias de processo, no universo do trabalho a sua repercussão é ainda muito limitada. Assim, serão apresentadas abaixo pesquisas com profissionais de saúde sob o crivo de teorias de conteúdo.

Sob a ótica da teoria de McClelland, uma pesquisa identificou níveis maiores de motivação de realização e níveis mais baixos para a motivação de afiliação e poder em enfermeiros de um hospital universitário do interior paulista (PASTI; GIR; COLETA, 1999).

BATISTA ET AL. (2005), a partir da teoria de Maslow, identificaram que, apesar da remuneração ser tida como fator de motivação, não é o principal, havendo ainda o gosto pelo trabalho, bom relacionamento com colegas e ser possível conseguir crescimento profissional.

Sob a luz da teoria dos dois fatores de Herzberg, outra pesquisa (PEREIRA; FÁVERO, 2001) apresenta, como formas de elevar a motivação o bom relacionamento interpessoal e uma melhor estruturação do trabalho. Ainda, sob a luz da teoria de Herzberg, outro estudo (BEZERRA ET AL., 2010) constatou que 60\% da população de enfermeiros consideravam suas equipes de enfermagem desmotivadas. As autoras afirmam que estes acreditavam ser devido à sobrecarga de trabalho, além do pouco reconhecimento de gestores e a falta de um bom relacionamento entre a gerência de enfermagem e a equipe assistencial. No entanto, $65 \%$ dos sujeitos apontavam como motivadores a construção conjunta de planos assistenciais, liderança democrática, bom relacionamento e reconhecimento.

\section{MÉTODO}

Esta é uma pesquisa exploratório-descritiva, de método hipotético-dedutivo, a partir do estudo da equipe de enfermagem de um hospital municipal do interior de Rondônia.

\section{Sujeitos}

O universo da população é de 61 profissionais, 8 de nível superior (enfermeiros), 47 de nível médio (técnicos de enfermagem) e 6 de nível fundamental (auxiliares de enfermagem). 
Em casos de desvio de função, no exemplo de técnicos de enfermagem que têm contrato para este cargo e atuam como enfermeiros, consideramos os mesmos enfermeiros, ou seja, a função que desempenham. Profissionais cedidos de outras instituições para o hospital pesquisado também foram incluídos.

A amostra foi composta conforme o Quadro 1, a seguir.

Quadro 1. Detalhamento da amostra na instituição pesquisada, no todo e em cotas, conforme formação profissional

\begin{tabular}{|l|r|r|r|r|}
\hline $\begin{array}{l}\text { Cotas da } \\
\text { população }\end{array}$ & $\begin{array}{r}\text { Universo da } \\
\text { população }\end{array}$ & Amostra & $\begin{array}{r}\text { Amostra em relação ao } \\
\text { universo da população em } \\
\%\end{array}$ & $\begin{array}{r}\text { Cota em relação à } \\
\text { amostra total em \% }\end{array}$ \\
\hline Enfermeiros & 8 & 3 & 37,5 & 37,5 \\
\hline $\begin{array}{l}\text { Técnicos de } \\
\text { enfermagem }\end{array}$ & 47 & 4 & 8,5 & 12,5 \\
\hline $\begin{array}{l}\text { Auxiliares de } \\
\text { enfermagem }\end{array}$ & 6 & 1 & 16,7 & 100,0 \\
\hline Total & 61 & 8 & 13,1 & \\
\hline
\end{tabular}

Tal composição da amostra em cotas procurou garantir a melhor representatividade possível, conforme a categoria ocupacional, apesar de tomar toda equipe como um todo para a análise. Naturalmente, se houverem diferenciações pertinentes, estas serão apresentadas.

\section{Instrumentos}

Os dados foram colhidos com a aplicação de um questionário sociodemográfico de autoria do pesquisador e utilizando-se o Inventário de Motivação e Significado do Trabalho (IMST), construído por BORGES E ALVES FILHO (2001, 2003). Este material congrega grandemente os aspectos da teoria da expectativa, também o construto significado do trabalho, que não foi abarcado neste estudo.

A estrutura do IMST contempla quatro escalas: de atributos valorativos (nesta pesquisa eleito equivalente à valência da teoria da expectativa), de atributos descritivos (este desconsiderado por não se inserir na abordagem teórica envolvida, pois se presta exclusivamente ao construto significado do trabalho), de expectativas (aqui equivalente à expectativa na teoria de Vroom) e de Instrumentalidade (que também se insere na teoria de Vroom). Será possível chegar, numa amplitude de 0 a 144, ao escore da força motivacional, resultado dos escores das escalas de expectativa, valência e instrumentalidade. 
Cada escala traz alguns fatores, compreendidos por BORGES E ALVES FILHO (2003) da seguinte forma:

Quanto à composição da escala de atributos valorativos:

- justiça no trabalho: diz respeito que o trabalho deve garantir condições ótimas ao colaborador, higiene, segurança, materiais conforme as atribuições exercidas, renda compatível às atividades desempenhadas e equilíbrio entre os esforços e os direitos do colaborador, em comparação aos colegas.

- autoexpressão e realização pessoal: se refere que o trabalho deve garantir o desenvolvimento do colaborador, expressão de sua criatividade e capacidade, além de proporcionar capacitação; incluindo, ainda, ter bom rendimento, prazer na execução das tarefas e desenvolvimento quanto às relações interpessoais.

- sobrevivência pessoal e familiar: define que o trabalho deve proporcionar a sustentação econômica, pessoal e familiar, desenvolvimento social, estabilidade por conta do rendimento do trabalhador e assistência pessoal e familiar.

- desgaste e desumanização: traduz que o trabalho deve propiciar desgaste, esforço físico, atarefamento, sentindo-se como uma máquina ou animal (desumanização).

Quanto à escala de expectativas:

- autoexpressão e justiça no trabalho: se refere à expectativa do colaborador de oportunidades para haver reconhecimento e demonstração de criatividade; mostrar responsabilidade e desempenho, merecendo a confiança de gestores; também espaço para desenvolvimento, através de capacitações, criar relações interpessoais positivas e influenciar no andamento de processos organizacionais.

- segurança e dignidade: indica o quanto o colaborador espera ter medidas de segurança na instituição e ser tratado como pessoa, com dignidade.

- desgaste e desumanização: diz respeito à expectativa do colaborador que o trabalho lhe traga esgotamento, pressa, ocupação e desumanização, sentindo-se como uma máquina ou animal.

- responsabilidade: traduz que o colaborador espera ser responsável pelas suas atividades, por decisões e, de forma geral, pelo que executa, respeitando a hierarquia.

Para a escala de instrumentalidade:

- envolvimento: define o quanto o colaborador percebe o próprio desempenho como determinante para a resolução de problemas, por sua responsabilidade de decisões, por sua dignidade e ajuste às normas, hierarquia, merecimento de confiança e inclusão.

- justiça no trabalho: define a percepção do desempenho como influência para obter, de forma igualitária aos colegas, conforto, equipamentos apropriados, direitos iguais, harmonia entre o esforço e recompensas e sua remuneração. 
- desgaste e desumanização: indica a percepção do próprio trabalho como acometedor de dor física, cansaço, esgotamento, atarefamento e pressa.

- reconhecimento e independência econômica: indica a percepção do colaborador de seu desempenho como forma de alcançar independência, manutenção da sua subsistência, conforto e status social, reconhecimento.

\section{Procedimentos}

Os participantes foram abordados por conveniência até atingir cada cota. Porém, as visitas se deram em três turnos distintos para garantir ampla possibilidade de participação.

Foram abordados 18 participantes, dadas as instruções e combinou-se de buscar o material uma semana depois. Entretanto, apenas os instrumentos respondidos por 8 participantes foram adequados à análise. Além da taxa de desistência e extravio na própria instituição, alguns não devolveram no prazo combinado e houve casos de questões sem resposta. Assim sendo, materiais de 2 participantes foram desconsiderados e de 8 outros participantes não foram recebidos até a apuração dos resultados.

\section{RESULTADOS}

A partir do questionário sociodemográfico verificou-se que a amostra tem $62,5 \%$ de participantes do sexo feminino e $37,5 \%$ do sexo masculino; $62,5 \%$ possuem idade entre 30 a 39 anos, $12,5 \%$ tem idade entre 18 a 29 anos e 12,5\% possui idade entre 40 a 49 anos. O tempo de serviço na instituição é de 5 a 10 anos para $62,5 \%$ dos participantes, havendo ainda $12,5 \%$ com tempo de 1 a 4 anos, $12,5 \%$ com 11 a 19 anos e $12,5 \%$ com 20 a 29 de casa. A renda é de até 3 salários-mínimos para $50 \%$ da amostra, $25 \%$ recebem entre 3 a 5 salários-mínimos e há $12,5 \%$ que recebe entre 6 a 8 e 12,5\% recebe entre 9 a 11. Trabalham em outras instituições 62,5\% dos sujeitos e outros $37,5 \%$ exercem sua atividade apenas na instituição pesquisada. Quanto ao vínculo empregatício, $12,5 \%$ é cedido, os demais foram contratados especificamente para a instituição, porém todos têm vínculo estatutário. Apenas 25\% dos participantes possuem formação acima da exigida para o cargo.

Serão apresentados nas Tabelas 2 a 5, abaixo, num intervalo de 0 a 4, os resultados dos escores médios dos participantes para os fatores que englobam as escalas do IMST.

Por fim, será apresentado o escore da força motivacional resultante na Tabela 4. Esta é categorizada em quatro intervalos $1=0$ a 35, 2= 35 a $70,3=70$ a 105 e 4= acima de 105 (BORGES; ALVES FILHO, 2003).

Tabela 1. Médias para a escala de atributos valorativos na instituição pesquisada 


\begin{tabular}{lr}
\hline Fatores & Médias \\
\hline autoexpressão e realização pessoal & 3,43 \\
Sobrevivência pessoal e familiar & 3,33 \\
Justiça no trabalho & 2,52 \\
Desgaste e desumanização & 1,70 \\
\hline
\end{tabular}

$\mathrm{Na}$ Tabela 1 pode-se perceber que os participantes valorizam, principalmente, a autoexpressão e realização pessoal, seguido por sobrevivência pessoal e familiar. Um escore menor foi obtido para o fator justiça no trabalho, menos valorizado, e muito menor para desgaste e desumanização.

Tabela 2. Médias para a escala de expectativas na instituição pesquisada

\begin{tabular}{lr}
\hline Fatores & Médias \\
\hline Segurança e dignidade & 3,37 \\
Autoexpressão e justiça no trabalho & 3,35 \\
Responsabilidade & 3,35 \\
Desgaste e desumanização & 2,43 \\
\hline
\end{tabular}

Os participantes esperam do trabalho, conforme Tabela 2, um lugar de segurança e dignidade, seguido por autoexpressão e justiça no trabalho e responsabilidade. Também esses profissionais esperam que haja certo desgaste e desumanização, mas moderadamente.

Tabela 3. Médias para a escala de instrumentalidade na instituição pesquisada

\begin{tabular}{lr}
\hline Fatores & Médias \\
\hline Envolvimento & 3,33 \\
Reconhecimento e independência & 2,98 \\
econômica & 2,43 \\
Desgaste e desumanização &
\end{tabular}


Para conseguir o que almejam, conforme Tabela 3, os participantes listam o envolvimento, depois o reconhecimento e independência econômica. Com escores mais baixos, os fatores desgaste e desumanização e justiça no trabalho são instrumentais citados, mas usados moderadamente.

Tabela 4. Médias para a força motivacional na instituição pesquisada

\begin{tabular}{lcr}
\hline Valores & Totais & Percentual \\
\hline Média & 82,02 & 56,95 \\
Valor mínimo & 56,85 & 39,47 \\
Valor máximo & 98,91 & 68,68
\end{tabular}

$\mathrm{Na}$ Tabela 4 temos representada a força motivacional na qual o escore mínimo foi de 56,85 (39,47\%), com valor máximo de 98,91 (68,68\%) e médio de 82,02 (56,95\%). Esta média está no intervalo $3=70$ a 105.

\section{DISCUSSÃO}

A partir dos dados é possível inferir que a motivação da população é considerada moderada a alta, se inserindo nos intervalos que a constituição do IMST propõe como $3=70$ a 105, porém mais próxima de um valor médio/razoável.

Quanto aos fatores mais relevantes para determinar o engajamento desses profissionais, pode-se inferir que os mesmos valorizam o próprio desenvolvimento em plenitude, sua realização profissional, através da criatividade, e valorizam o proativismo (valência); esperam ocorrer condições adequadas e dignas para o exercício da profissão (expectativas); e se integram aos colegas e à instituição em sua atividade laboral, afetiva e efetivamente, como forma de conseguir o que almejam (Instrumentalidade).

Em comparação com resultados de outras pesquisas, GUARDA (2009) também identificou o fator envolvimento da escala de instrumentalidade em seu estudo com médicos. Na pesquisa de BORGES E ALVES FILHO (2003) é possível visualizar resultados parecidos, quanto aos escores, para cada fator das escalas, com poucas exceções, também diferindo quanto à hierarquia, em alguns casos. Porém, mais uma vez, o envolvimento, tal qual em GUARDA (2009), está no topo da hierarquia da escala de instrumentalidade. Os dois estudos também resultaram em médias de força motivacional muito similares ao desta pesquisa. 
Tais aspectos, não parecem diferir dos resultados das pesquisas de PEREIRA $\mathrm{E}$ FÁVERO (2001), BATISTA ET AL. (2005) e de BEZERRA ET AL. (2010), apesar das diversas linhas teóricas. Onde, o gosto pelo trabalho, bom relacionamento com colegas de equipe e bom relacionamento interpessoal são fatores que promovem maior engajamento no trabalho; algo próximo do fator envolvimento.

Cabe partir para os aspectos teóricos do modelo contingencial de Vroom, este propõe um processo na qual a motivação é determinada pelo retorno que o trabalho propicia (resultados do trabalho), a partir daquilo que é esperado (expectativa), fazendo-o dar um maior desempenho (instrumentalidade), assim o profissional valoriza aspectos no trabalho que mais lhe trazem resultados (valência). Nesse sentido, é possível visualizar claramente médias altas em vários fatores da escala de expectativas, já na escala de instrumentalidade percebem-se médias menores. Isso, para CALDAS E ALVES FILHO (2007), pode ter influência negativa na motivação dos indivíduos, pois estes não visualizam tão claramente o próprio desempenho como instrumental para conseguirem aquilo que desejam, fazendo o seu trabalho parecer obsoleto na sua realização pessoal.

Ainda, quanto à instituição, é interessante para esta a implantação de uma gestão de pessoas segundo a teoria da expectativa. Tal proposta pode ser exemplificada em ações integrativas, já que envolvimento é citado fortemente como instrumental para a realização das expectativas desses colaboradores. Esse aspecto se relaciona fortemente com um ambiente humanizado, que aqui pode ser considerado como um dos objetivos da organização. Este seria um exemplo de vinculação de objetivos organizacionais com as expectativas dos colaboradores, entre outras proposições possíveis, a partir dessa teoria aplicada à gestão de pessoas.

\section{CONSIDERAÇÕES FINAIS}

Com relação à instituição pesquisada, é interessante que se atente para a motivação dos seus profissionais de enfermagem, já que a força motivacional, apesar de estar num intervalo alto, se aproxima de um valor moderado/razoável.

O maior aspecto crítico na pesquisa, no entanto são as médias menores na escala de Instrumentalidade, que denunciam que os colaboradores visualizam pouco seu desempenho como forma de alcançar o que almejam. É importante para a organização que possibilite meios para essa percepção ser mais clara. Se o trabalho não é instrumental para o alcance do que se almeja ele perde muito de sua força motivacional.

Quanto às dificuldades na pesquisa, as maiores foram com relação à aplicação do instrumento, com atrasos e preenchimentos incorretos, levando ao descarte de alguns materiais. Tais dificuldades se devem à dimensão do material e, portanto, não há o que fazer senão persistir na coleta de dados e na sensibilização dos participantes.

Para futuros estudos nesta população, sugestões de pesquisas são as que tratam do significado do trabalho, permitindo a visualização de um panorama mais amplo do contexto laboral destes colaboradores. 


\section{REFERÊNCIAS}

ARAÚJO, L. C. G. Gestão de pessoas. São Paulo: Atlas, 2008.

BATISTA, A. A. V. et al. Fatores de motivação e insatisfação no trabalho do enfermeiro. Rev. Esc. Enferm. USP, São Paulo, v. 39, n. 1, p. 85-91, mar. 2005. Disponível em: <http://www.scielo.br/pdf/reeusp/v39n1/a11v39n1.pdf>. Acesso em: 6 maio 2016.

BEZERRA, F. D. et al. Motivação da equipe e estratégias motivacionais adotadas pelo enfermeiro. Rev. Bras. Enferm., Brasília, v. 63, n. 1, p. 33-37, jan./fev. 2010. Disponível em: <http://www.scielo.br/pdf/reben/v63n1/v63n1a06.pdf>. Acesso em: 6 maio 2016.

BORGES, L. O.; ALVES FILHO, A. A mensuração da motivação e do significado do trabalho. Estud. Psicol. (Natal), Natal, v. 6, n. 2, p. 177-194, jul./dez. 2001.

Disponível em: <http://www.scielo.br/pdf/epsic/v6n2/7272.pdf>. Acesso em: 3 mar. 2016.

. A estrutura fatorial do inventário do significado e motivação do trabalho, IMST. Aval. Psicol., Porto Alegre, v. 2, n. 2, dez. 2003. Disponível em: $<$ http://pepsic.bvsalud.org/pdf/avp/v2n2/v2n2a04.pdf>. Acesso em: 3 mar. 2016.

CALDAS, R. K. P.; ALVES FILHO, A. Fatores motivacionais determinantes para o vínculo com o trabalho. Revista da FARN, Natal, v. 6, n. 1/2, p. 53-67, jan./dez. 2007. Disponível em: $<$ http://www.revistaunirn.inf.br/revistaunirn/index.php/revistaunirn/article/download/12 1/135>. Acesso em: 29 mar. 2016.

CHIAVENATO, I. Recursos humanos: o capital humano das organizações. 9. ed. Rio de Janeiro: Elsevier, 2009.

Gestão de pessoas: o novo papel dos recursos humanos nas organizações. 3. ed. Rio de Janeiro: Elsevier, 2010.

GIBSON, J. L. et. al.Organizações: comportamento, estrutura e processos. 12. ed. São Paulo: McGraw-Hill, 2006.

GONDIM, S. M. G.; SILVA N. Motivação no trabalho. In: ZANELLI, J. C.; BORGESANDRADE, J. E.; BASTOS, A. V. B. (Org.). Psicologia, organizações e trabalho no Brasil. Porto Alegre: Artmed, 2004. p. 145-176.

GUARDA, F. R. B. Perfil sócio-demográfico e motivação dos médicos que compõem equipes de saúde da família na região metropolitana do Recife. [Dissertação] Recife: Fundação Oswaldo Cruz, 2009. Disponível em:

<http://www.cpqam.fiocruz.br/bibpdf/2009guarda-frb.pdf>. Acesso em: 29 mar. 2012.

MARCONI, N. A evolução do perfil da força de trabalho e das remunerações nos setores público e privado ao longo da década de 1990. Revista do Serviço Público, Brasília, ano 54, n. 1, p. 9-45, jan./mar. 2003. Disponível em: 
$<$ http://www.enap.gov.br/index.php?option=com docman\&task=doc view\&gid=3004 >. Acesso em: 2 abr. 2012.

MARRAS, J. P. Administração de recursos humanos: do operacional ao estratégico. 3. ed. São Paulo: Futura, 2000.

PASTI, M. J.; GIR, E.; COLETA; J. A. D. Perfil motivacional do enfermeiro atuante em um hospital geral do interior paulista. Rev. Latino-Am. Enfermagem, Ribeirão Preto, v. 7, n. 5, p. 33-41, dez. 1999. Disponível em:

<http://www.scielo.br/pdf/rlae/v7n5/13502.pdf>. Acesso em: 6 maio 2012.

PEREIRA, M. C. A.; FÁVERO, N. A motivação no trabalho da equipe de enfermagem. Rev. Latino-Am. Enfermagem, Ribeirão Preto, v. 9, n. 4, p. 7-12, 2001. Disponível em: <http://www.scielo.br/pdf/rlae/v9n4/11476.pdf $>$. Acesso em: 6 maio 2016.

PÉREZ-RAMOS, J. Motivação no trabalho: abordagens teóricas. Psicol. USP, São Paulo, v. 1, n. 2, p. 127-140, dez. 1990. Disponível em:

$<$ http://pepsic.bvsalud.org/pdf/psicousp/v1n2/a04v1n2.pdf >. Acesso em: 3 mar. 2016.

ROBBINS, E. P. Comportamento organizacional. 11. ed. São Paulo: Pearson Prentice Hall, 2005.

SILVA, W. C. M. Motivação nas organizações: um estudo em organização pública do poder legislativo. Brasília, 2006. Disponível em:

$<$ http://bd.camara.gov.br/bd/handle/bdcamara/4403>. Acesso em: 30 abr. 2016.

VROOM, V. H. Work and motivation. Nova York: Wiley, 1964.

Recebido: 23 junho 2017. Publicado: 03 outubro 2017

Correspondência: Luciano Santos Magalhães. E-mail: lucianomagalhaes@unir.br

Conflito de Interesses: os autores declararam não haver conflito de interesses

(C) This is an Open Access article distributed under the terms of the Creative Commons Attribution License, which permits unrestricted use, distribution, and reproduction in any medium, provided the original work is properly cited 